\title{
Micro- and Macrodata: a Comparison of the Household Finance and Consumption Survey with Financial Accounts in Austria
}

\author{
Michael Andreasch ${ }^{1}$ and Peter Lindner ${ }^{2}$
}

\begin{abstract}
This article compares the results of Austria's Household Finance and Consumption Survey (HFCS) on savings deposits and estimates on total financial assets with administrative records from the national accounts for the household sector. The microdata that are newly generated through the HFCS and the detailed (internally available) breakdown of savings deposits in the existing macrodata (financial accounts) lend themselves to a more in-depth analysis of the similarities and differences in these two sources. Comparing the data shows that the HFCSbased aggregate estimates are lower than the financial accounts data, which is in line with evidence from the literature. The article also shows, however, that the survey adequately captures the underlying patterns at the microlevel in terms of the overall financial portfolio allocation and the distribution of savings deposits over detailed breakdowns. Moreover, a simulation based on the HFCS data demonstrates the effect that the inclusion of savings deposits in the most affluent tail of the distribution has on common statistics. Undercoverage above all of the upper deposit ranges suggests an underestimation or bias in the statistics. This underestimation, however, can be shown to be relatively minor, particularly in the case of robust statistical measures, such as the median or percentile ratios.
\end{abstract}

Key words: Wealth distribution; survey; national accounts.

\section{Introduction}

In recent years, survey data have become an important tool in the research on assets and debt. The data often constitute the only pool of data on household assets that is collected systematically at the microlevel. Yet the tradition of surveys on household assets is shorter than that of income surveys. For this reason, survey data on incomes have been compared with income data from other sources more frequently and in greater detail in the literature. The innovation of the Household Finance and Consumption Survey (HFCS), which covers the entire eurozone, is that it provides a harmonised framework for collecting information on eurozone household (financial and nonfinancial) assets and liabilities, which represents a basis for eurozone-wide analyses.

1 Oesterreichische Nationalbank, External Statistics, Financial Accounts and Monetary, and Financial Statistics Division. Otto-Wagner-Platz 3, 1090 Vienna, Austria. Email: michael.andreasch@ oenb.at

2 Oesterreichische Nationalbank, Economic Analysis Division, Otto-Wagner-Platz 3, 1090 Vienna, Austria. Email: peter.lindner@oenb.at

Acknowledgments: We would like to thank Nicolás Albacete, Pirmin Fessler, Martin Schürz and four anonymous referees for very helpful discussions and comments. In addition to the usual disclaimer, the opinions expressed in this study solely represent those of the authors and do not necessarily reflect the official viewpoint of the Oesterreichische Nationalbank or of the Eurosystem. 
Although all forms of data compilation come with their own specific problems, some difficulties attached to surveys attract special criticism, such as nonparticipation or nonresponse. A key criticism is that households often decline to participate in voluntary surveys or that, if they do agree to participate, they provide incorrect information or refuse to respond to specific questions. In addition, the survey methods may influence results from survey data, for example, the interview mode (see Fessler et al. 2012). Hence, to identify the strengths and possible weaknesses of the HFCS data, it is useful to compare them thoroughly with other national statistics. In doing so, we also need to bear in mind that the macrodata exhibit certain weaknesses. The most obvious one is that data from financial accounts are (publicly) only available at the aggregate level and thus it is not possible to carry out a distributional analysis. Additionally, there are also issues concerning classification of the data (households vs. self-employed businesses/ other institutions) and estimations (e.g., cash holdings). Thus it is far from clear that one or the other source of data present a better choice for all investigations, and so comparing the results of the HFCS survey with other national statistics will contribute to a better understanding of the economy, as different data sources tend to generate complementary findings.

Furthermore, in the light of the "Report by the Commission on the Measurement of Economic Performance and Social Progress" by Stiglitz et al. (2009), which recommended to "[g]ive more prominence to the distribution of income, consumption and wealth" (Recommendation 4 on page 13), our understanding of the integration of micro- and macrodata must be analysed and enhanced. This analysis also contributes to the effort of international institutions such as the ECB to integrate information from the macro- and the microlevel to a greater extent. Furthermore, in light of the "Beyond GDP" initiative of the European Commission, the analysis at hand can be viewed as a first step towards an approach integrating micro- and macrostatistics. Before a clear view of the overall picture can be gained, we need to understand the similarities and differences between the existing information in detail.

One of the general results documented here is evidence that the HFCS in Austria underrepresents households' financial assets: total financial assets as identified by the HFCS come to roughly $40 \%$ of total financial assets as shown by the financial accounts (Section 4.1). Essentially, this finding corresponds to similar comparisons of survey data and administrative records described in the literature (Section 2). Owing to the internal availability of administrative records on financial wealth, the article contributes to the existing literature in the following ways. First, we compare the allocation of savings over different deposit ranges and different sectors of the Austrian banking system, as these are recorded by both the HFCS and existing national statistics (hence the article goes beyond a comparison of the aggregate statistics). We find that the deposit patterns are similar in both the survey data and the banks' reports. Furthermore, a microsimulation of the upper deposit amounts, which are underrepresented in the HFCS, shows that the ensuing (negative) bias is relatively low for statistical robust estimates in particular. Thus, depending on the issue under research, both the aggregated data of the national accounts and the HFCS data represent a valid basis for empirical evaluations. The results presented in this analysis should provide a good understanding of the relationship of the micro- and macrodata of other eurozone countries due to the 
harmonised manner of data collection and the similar relative importance of the major components.

This article is structured as follows. In Section 2, we establish a link between the article and the existing literature. Section 3 provides an explanation of the data used. The results of the comparison are presented in Section 4. In addition to the evaluation of aggregate results, we provide a comparison of the HFCS data with the banking statistics in a detailed breakdown of deposits on savings accounts. The simulation of the upper savings deposit ranges along with the evaluation of the impact of undercoverage on the main estimators is set out in Section 5. The analysis concludes with final remarks and suggestions for further research.

\section{Background}

Comparisons of survey data with data derived from administrative sources are common in the scientific literature. As data on flows of the household balance sheet, in particular from administrative sources, are more readily available than data on household stocks, most studies limit themselves to evaluating information on incomes. The literature comparing income in survey and administrative data is able to provide a broader picture of relevant ideas for investigations concerning the stocks of the household balance sheet, such as the present article.

In summary, income data from both survey and administrative sources are subject to errors, the resulting bias of the estimators is expected to be low, and, in most studies, the differences between the data result from specification differences (definitions of the unit of collection, of types of income, etc.). As a case in point, Törmälehto (2011) compares the data collected by the Luxembourg Income Study Group (LIS) with income aggregates in the national accounts. He observes that surveys capture over $90 \%$ of income in most countries, admittedly with a lower degree of coverage in some income subcategories. For the United States, Davies and Fisher (2009) find some differences between individual income sources using data from the Current Population Survey (CPS) and the Survey of Income and Program Participation (SIPP) matched with administrative data from the social security administration. Using the same datasets, Roemer (2002) shows that the surveys accurately capture the underlying patterns of income distribution. Roemer also points out the problems underlying income distributions based on administrative data (e.g., because illegal work and related income are not captured in the administrative data). Kavonius and Törmälehto (2003) compare income aggregates of various sources from survey data (e.g. Income Distribution Survey) with national accounts data for Finland. While wages and salaries are nearly identical in both data sources (survey coverage is about $99 \%$ ), the data for property income and self-employment income differ substantially (unadjusted coverage is $210 \%$ and $52 \%$, respectively). Bricker and Engelhardt (2008) report on measurement error in earnings data for men and for women in the United States, comparing administrative records of the Social Security Administration (SSA) and of the Internal Revenue Service (IRS) with the survey data in the Health and Retirement Study (HRS). As the data can be precisely matched, the authors are able to identify a measurement error of about six percent in men's incomes and of approximately seven percent in women's incomes. Finally, Kapteyn and Ypma 
(2007) research measurement error on the basis of data from the Swedish Longitudinal Individual Data Base (LINDA) compared with information from the Survey of Health, Ageing, and Retirement in Europe (SHARE). The authors show that erroneous observations lead to biased estimators in a variance analysis. Errors are found not just in survey data, but also in the administrative data.

The literature has not produced as many findings on stocks of the household balance sheet. Avery et al. (1988) were the first to compare aggregate estimates based on survey data with national accounts data (i.e., flow-of-funds statistics). The authors show that aggregate savings deposits as documented by the Survey of Consumer Finance (SCF) amounted to less than $50 \%$ of aggregate savings deposits as captured by the flow-offunds statistics. However, the discrepancy between the two data sources with regard to the household wealth held in the households' main residence offsets this difference. Thus the estimate of households' gross assets is quite similar in both data sources. Similarly, Antoniewicz et al. (2005) examined the coverage of financial assets and liabilities of the household sector in three surveys performed for Italy, the United States, and to some extent for Canada. With regard to Canada, where data were available for 1999, the microdata on deposits and total liabilities were around 30\% lower than the macrodata. This result is echoed by the microdata for Italy, which are based on the Survey on Household Income and Wealth (SHIW): the estimate for total financial assets in the SHIW came to $31 \%$ of the corresponding macrodata. However, an adjustment for underestimation and nonresponse produces a significant improvement of underreporting. In the United States, the survey data (SCF) are closer to the flow-of-funds data. In a more recent paper based on the same data, Henriques and Hsu (2014) show additionally that the changes in the aggregate values over time are broadly synchronized. Sierminska et al. (2006) compare the data of the Luxembourg Wealth Study (LWS) for several countries with national statistics. The authors show that the varied sources on which the LWS database is based capture between $13 \%$ and $117 \%$ of per capita household wealth. The administrative data are subject to some problems, so that an estimate of per capita household wealth in the LWS database equalling $117 \%$ of the estimate based on national statistics is not necessarily a sign of a lack of quality of the surveys used. With a ratio of the LWS database to the national balance sheet of between $65 \%$ and $117 \%$, the match between the micro- and macrodata of nonfinancial assets is closer than that of financial assets (with an LWS to NBS ratio of between $13 \%$ and 52\%). Finally, Johansson and Klevmarken (2007) used information from the administrative LINDA database and from two surveys conducted in Sweden (both refer to residents aged 50 and over) to identify measurement error, its correlation with the volume of assets, and the effects on regression analyses. The authors concluded that measurement error correlated with the volume of assets occurs above all at the tails of the distribution. In an independent effort at approximately the same time as this article was written, Kavonius and Honkkila (2013) looked at the comparison of the HFCS with National Accounts for Finland, Italy and the Netherlands. However, Kavonius and Honkkila (2013) only look at a comparison of aggregated values. The analysis below extends the literature by looking at detailed categories in terms of asset ranges and banking sectors on the one hand, and by simulating the potential impact of the highest saving levels on commonly used statistics on the other hand. 


\section{Data and Definitions}

This analysis is based on two different datasets from Austria, data derived from the HFCS and administrative banking statistics used to compile the financial accounts. Both types of data are compiled and managed by the Oesterreichische Nationalbank (OeNB). The breakdown in both the microdata and macrodata permits a granular analysis of the interlinkages. Appendix A provides the details of the breakdown by banking sector and assets ranges.

\subsection{The HFCS in Austria}

The first wave of the HFCS is the most comprehensive survey on household assets and debt to be conducted in Austria. Of a stratified cluster random sample of 4,436 households, 2,380 households agreed to participate in the voluntary survey and were interviewed in person (CAPI - Computer-assisted personal interviewing) about the different components of household assets and liabilities among other things. The field phase was conducted from the third quarter of 2010 to the second quarter of 2011. The reference period for stock information is the time of the interview. Most of the missing information (i.e. information not provided by respondents) was imputed using a Bayesian-based multiple-imputation procedure (this is explained in more detail below). On the basis of sample design weights and after nonresponse adjustment, the final household weights used in the evaluations in this analysis were poststratified both by regional distribution of the households and by distribution of household size (see Albacete et al. (2012) and Fessler et al. (2012)). In particular, this means that the weights were not adjusted to meet the aggregates or the structure of wealth and debt positions of an administrative data source. Hence, differences between the two separate data sources are to be expected; they have not been reduced or ruled out ex ante in the production process.

\subsection{The Financial Accounts in Austria}

The financial accounts are an integral part of the national accounts and as such are compiled in accordance with the rules of the European System of National and Regional Accounts 2010 (ESA 2010) based on data derived from a variety of administrative sources. In particular, the following components are used for the compilation of the data on deposits:

- The OeNB's financial statements,

- MFI (monetary financial institution) balance sheet statistics,

- supervisory statistics of banks resident in Austria,

- quarterly/annual balance of payments and international investment position data.

We used the financial accounts data for the reporting date 31 December 2010 (i.e., in the middle of the field phase of the HFCS) for comparison with the HFCS results. The focus of our analysis is not just on establishing the discrepancies between the aggregate values - as documented in the international survey literature - but above all on assessing the allocation of deposits to small ranges of volume and to the different sectors of the Austrian banking system. These data from the banking statistics are an important component of the financial accounts. This approach allows for the documentation of new 
and more detailed findings on the similarities and differences between macro- and microdata.

\subsection{Definition of the Unit of Collection}

The household represents the unit of collection in the HFCS. All households in Austria (except institutionalized households living, for example, in a home for the elderly, a monastery, military compound, or prison) are part of the target population, irrespective of their nationality, and thus have a positive probability of being selected for the HFCS sample.

By contrast, the banking statistics in the financial accounts capture the information on (euro-denominated) savings accounts, not by households but by accounts. These accounts can be allocated to the sector of (domestic) households and self-employed persons. The reports cover the accounts of all Austrian residents (persons or institutional units). The household sector includes consumer households, self-employed persons and sole proprietorships. Financial assets and liabilities for the self-employed businesses are shown on a gross basis in the financial accounts. In the HFCS, wealth of self-employed persons and sole proprietorships is classified as net wealth in self-employment business, that is, total assets (real and financial) minus liabilities, and is not recorded as part of the financial wealth but rather as real assets.

Household level in the survey and deposit account in the banking statistics are obviously two different units of observation. Despite the fact that it is the only possible way to compare savings from the two sources in detail as is done in this analysis, there are further reasons why this distinction does not render the analysis meaningless. As will be shown below, households have more than one account, but most households only use one bank, so the categorisation into banking sector is not affected to a large extent by the unit of observation. Furthermore, although shifts in asset ranges to higher ones might be expected in the survey due to aggregation of accounts, we would argue that the comparison of the detailed ranges is still valuable, since a lot of findings such as missing information in some ranges in the survey still provide important information independent of the discrepancy of the unit of observation. One can estimate how much is missing solely because of ranges with no observations in the survey, for example. Furthermore, bearing the unit of observation in mind allows us to see whether the aggregation at the household level yields the expected results, such as higher average values.

\section{Results of the Comparison of HFCS and Financial Accounts Data}

\subsection{Aggregates}

Major aggregate components of financial assets classified in the financial accounts can be estimated from the HFCS as well. The definitions of the information collected in the HFCS and reflected in the macrostatistics of the financial accounts are broadly comparable. Kavonius and Törmälehto (2010) have documented the link between the HFCS variables and the ESA definitions in detail, and so the links are not explained again. The following picture emerges for Austria (Table 1), with the top part of the table showing 


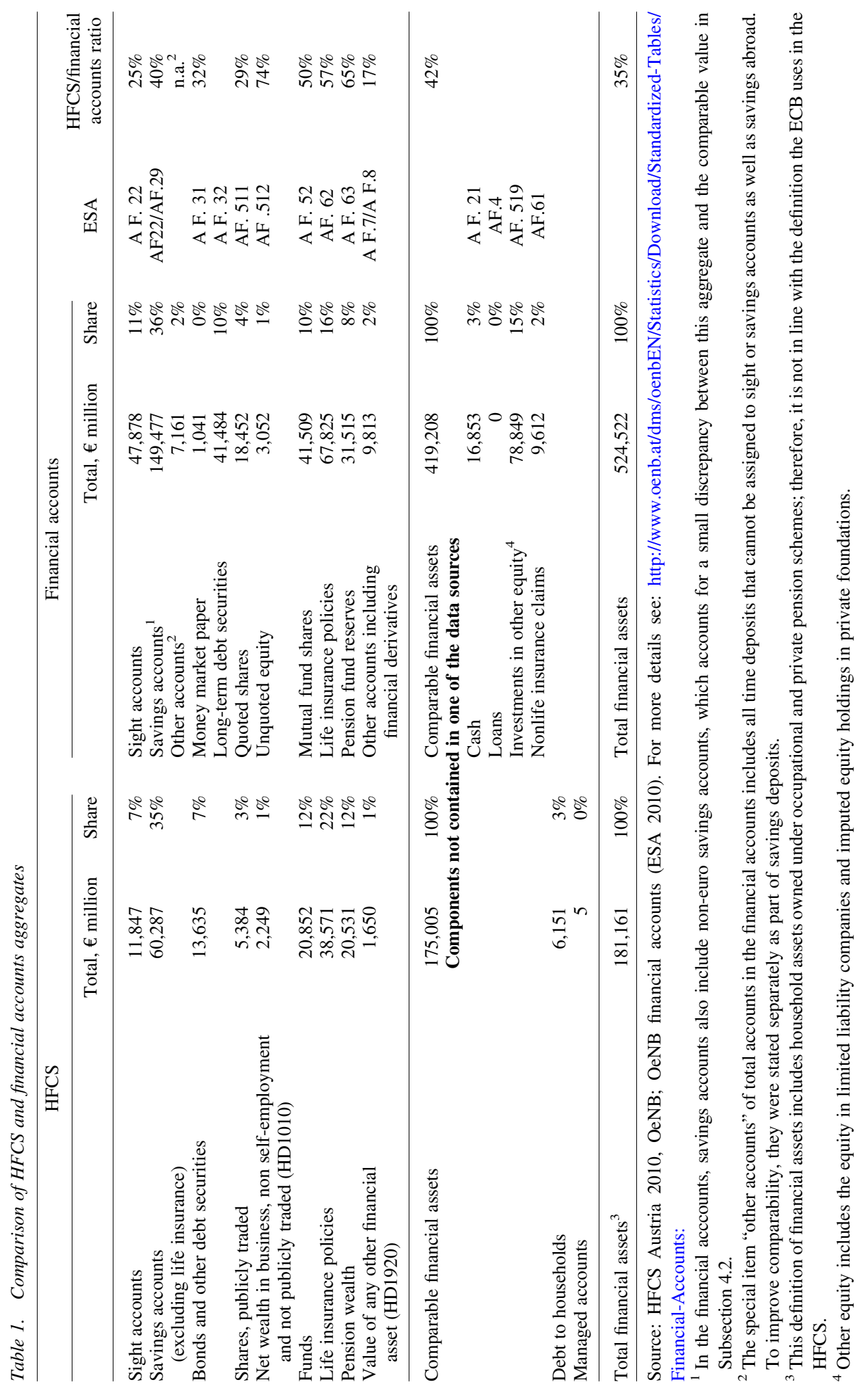


the comparable components, including the share of each component in terms of total comparable financial wealth and the bottom part showing the components that are not covered by one of the two data sources.

As common in the literature, the comparison of survey data (HFCS) and financial account aggregates indicates underreporting of household financial wealth in the HFCS in Austria. Table 1 indicates that the HFCS aggregate for comparable household financial wealth in Austria runs to about $42 \%$ of the financial accounts aggregate. This value may be considered fairly high in an international comparison with other surveys (see also Section 2). Sierminska et al. (2006) for example shows ratios ranging from $13 \%$ (United Kingdom, BHPS 2000) to 52\% (Norway, IDS 2002) and Mathä et al. (2012) indicate a ratio of $35 \%$ for the HFCS in Luxembourg. The possible origins of this difference are manifold; on the one hand the survey estimates might not cover the totality of the financial assets, but on the other hand the financial accounts data do not reflect solely the financial wealth of households as they include self-employed business assets and single-person companies and thus overestimate the households' financial wealth. However, the table indicates that (i) the distribution of the individual components of comparable financial assets in the HFCS data broadly mirrors the financial accounts patterns (see columns headed "share") and that (ii) the coverage ratio of the HFCS compared with the financial accounts varies considerably for individual financial instruments and components (see column headed "HFCS/financial accounts ratio").

The HFCS/financial accounts coverage ratio for savings deposits runs to $40 \%$. It must be noted, though, that the administrative records on total deposits also include the deposits of self-employed persons and sole proprietorships (accounting for $€ 13$ billion at the end of 2013), which the HFCS classifies as net investment in self-employment business, that is, as real assets. In the HFCS, the volume of life insurance holdings (representing the second-highest shares in both data sources) is calculated as the accumulated premia over the time span of the contract up to the time of the interview. The financial accounts data are based on insurance technical reserves comprising provisions for prepayments of premia (the difference between premia recognised and premia earned) and actuarial reserves (current value of expected future benefits); they may also include life insurance provisions if policyholders bear the investment risk. The HFCS captures premia, but no profit participation or service charges of the insurance providers. In addition, the value of life insurance holdings can fluctuate in the case of unit- and index-linked life insurance contracts.

Certain subcomponents are not covered by either of the two data sources. For instance, in the financial accounts, financial wealth resulting from the debt of a household to the respondent's household is not covered, as relevant data are not available. However, the HFCS shows that this component has a non-negligible volume. The HFCS did not include a question on cash holdings, as this question was considered to be too sensitive. In the financial accounts, the category "cash holdings" is calculated based on the estimated proportion of total financial assets adjusted by the change in cash requirements for consumption.

Figure 1 shows the relative importance of the major components of financial wealth for all countries covered in the HFCS. The similarity of the overall distribution of components of comparable financial wealth holds not only for Austria, but for all countries 


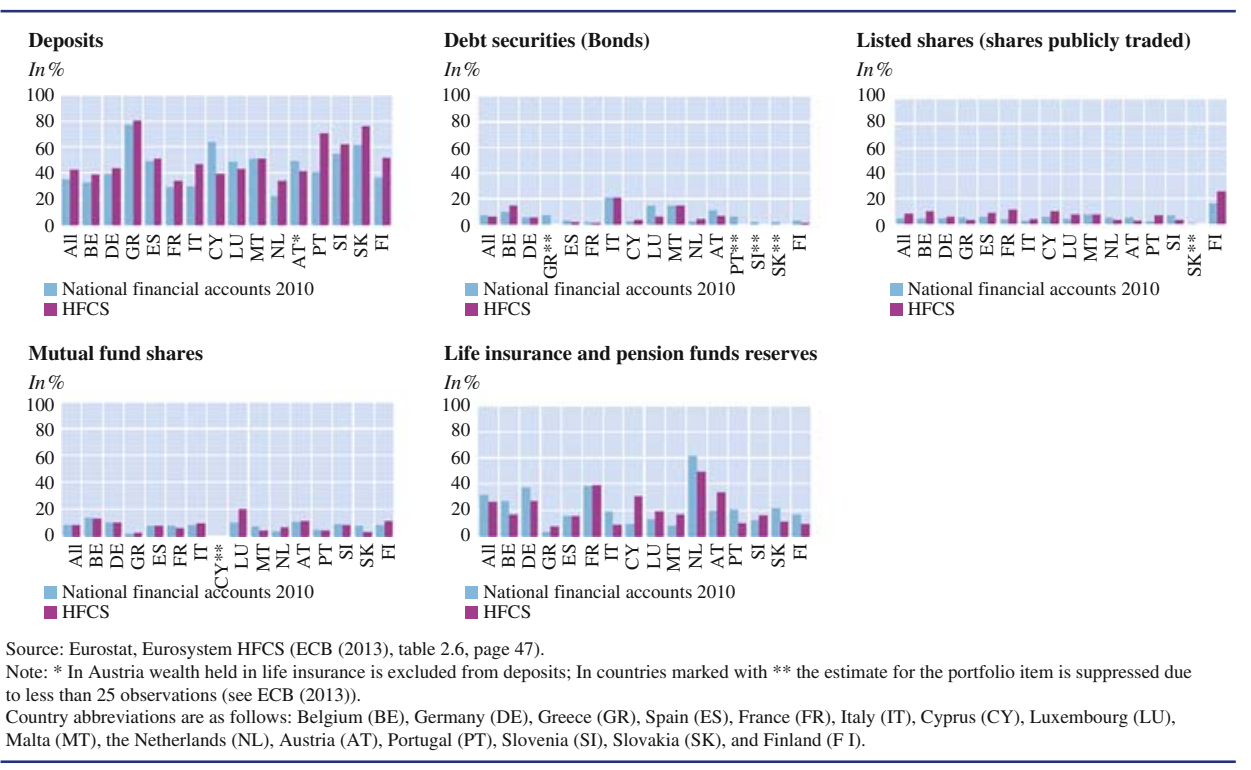

Fig. 1. Proportion of financial asset categories as share of total financial assets

participating in the HFCS across the board. Deposits (sight and savings accounts together) account for some $42 \%$ of financial wealth in the HFCS and some $47 \%$ in the financial accounts in Austria. Thus, these holdings make up the largest share of financial assets. Consequently, the analysis of this component of financial wealth has a greater explanatory weight (see Andreasch et al. (2009) for a comparison of survey data and administrative data on investments in selfemployment businesses). Given the fact that a breakdown of deposits compiled in macrodata by individual households is not possible, the attempt was made to find reasons for the discrepancies in the total volume by the analysis of data by individual banking sectors and asset ranges. This breakdown is available in both sets of data sources. In addition, the macrodata broken down by banking sectors are further disaggregated in different ranges of level of deposits, including the number of accounts allowing the estimation of the average amount for each range of deposit.

With some exceptions, the structural pattern in other countries seems to broadly reflect what is found in Austria. Hence - together with the ex-ante harmonisation of the HFCS we are convinced that the remaining results in this study are a reasonable indication for other countries as well. In the following, we are able to extend the literature by making use of the detailed administrative records with respect to savings accounts.

\subsection{Comparison of Savings Deposits}

\subsubsection{Historical Background and Imputations}

In the Austrian financial landscape, savings accounts for a very long time enjoyed a special position, as depositors were able to hold numbered accounts and thus remain anonymous. Opening anonymous accounts has been prohibited by law since 2000; and since then 
customers have been required to provide identification when opening an account. In theory, it is still possible to hold anonymous accounts even today, as the requirement imposed on banks is to identify accounts only if there are withdrawals or payments into the account. Additionally, the identification of existing savings accounts is reported to the Austrian Federal Ministry of the Interior only for withdrawals from deposit accounts with an amount of above $€ 15,000$. The historical development of identification requirements for savings accounts and the tradition of keeping information about household wealth, especially savings, confidential - households consider this information personal and sensitive - explains households' reluctance to provide information on the volume of holdings in savings accounts in the survey.

Based on the flags which describe the origin of every observation and used for the variable for deposits on savings accounts (HD1210), Table 2 shows that (only) about $56 \%$ of respondent households provided the exact amount of holdings in savings accounts. Approximately four percent of households could not ("don't know") and about ten percent did not want to ("no answer") provide data. An additional $16 \%$ of households provided range estimates, as they were unable to indicate specific amounts. This shows that in a voluntary survey like the HFCS, not only unit nonresponse (refusal to participate) but also item nonresponse (refusal to answer particular questions) represents a difficulty, especially when questions cover such sensitive issues. As the (partial) lack of answers cannot be considered purely random, the exclusion of these households (commonly referred to as "listwise deletion" or "complete case analysis" in the literature) results in a distortion of the estimators. Thus, in line with the procedures applied in the recent literature, the missing information in the HFCS was imputed using Bayesian-based multiple imputation (see Albacete et al. 2012 for an in-depth explanation of the imputation procedure applied). The estimations in this study take the multiple-imputation structure and survey design into account.

\subsubsection{Comparison of Number of Accounts}

The banking statistics documented roughly 23.5 million savings accounts as of the end of 2010, and according to information provided by Statistics Austria, some 8.4 million persons (3.7 million households according to the HFCS estimate) live in Austria. Hence, many persons have several savings accounts, but the amounts held in these accounts are

Table 2. Share of imputed observations

\begin{tabular}{lrr}
\hline & Number & Share \\
\hline Not applicable (no value due to use of filter) & 295 & $12.4 \%$ \\
Value collected, complete observation & 1,321 & $55.5 \%$ \\
Edited, value collected was incorrect & 2 & $0.1 \%$ \\
Imputed, originally - Don't know & 83 & $3.5 \%$ \\
Imputed, originally - No answer & 244 & $10.3 \%$ \\
Imputed, originally not collected due to higher order missing & 38 & $1.6 \%$ \\
Imputed, originally collected from a range or from brackets & 381 & $16.0 \%$ \\
Imputed, collected value deleted or value not collected due & 16 & $0.7 \%$ \\
$\quad$ to CAPI error & & \\
Total & 2,380 & $100 \%$ \\
\hline
\end{tabular}

Source: HFCS Austria 2010, OeNB. 
fairly small (see Table 3: roughly $81 \%$ of accounts contain deposits of less than $€ 10,000$ ). The reasons for having more than one savings account can be summed up as follows:

- Savings plans with building societies are separate savings accounts subject to special tax treatment. Therefore, many persons (Austrian citizens) have at least two savings accounts, one being a savings plan with a building society and the other a standard savings account. Customers typically attribute their building society savings plan to their house bank even though legally speaking, the deposits are held with another bank (a building society).

- Furthermore, security deposits for rental apartments are frequently kept on a separate savings account.

- As account maintenance charges are low (some Austrian banks do not charge any maintenance fees for accounts), people often have several savings accounts so that they can react quickly to interest rate differentials.

- Separate savings accounts (and partly also savings plans with building societies) are also kept for children.

- In addition, some account holders may have in fact forgotten they have accounts with very small holdings, so that the banking statistics may overrepresent actively held savings accounts. These forgotten accounts are by law kept alive for 30 years upon which they expire if no bank transfer (apart from interest payment) occurs in this period. Especially in the lowest deposit categories, the number of accounts may be distorted upward in the banking statistics in terms of active accounts.

Table 3 shows the distribution of the number of savings accounts by deposit holdings. The number of savings accounts is not explicitly asked for in the HFCS. However, the number of customer relationships households in Austria have with different banks can be estimated. The result of this calculation on the basis of HFCS data is displayed in the first column of Table 3, which indicates the number of customer relationships broken down by deposit ranges and the sum total of about 4.2 million of these relationships, which compares with about 23.5 million accounts in the financial accounts. Moreover, the table shows that the aggregation of potentially many accounts results in a higher percentage of

Table 3. Number of customer relationships with a bank/savings accounts

\begin{tabular}{|c|c|c|c|c|}
\hline & \multicolumn{2}{|c|}{ HFCS } & \multicolumn{2}{|c|}{ Banking statistics } \\
\hline & Total & Share & Total & Share \\
\hline All accounts & $4,205,802$ & $100.0 \%$ & $23,463,618$ & $100.0 \%$ \\
\hline Up to $€ 10,000$ & $2,653,396$ & $63.1 \%$ & $19,058,885$ & $81.2 \%$ \\
\hline$€ 10,000$ to $€ 20,000$ & 637,071 & $15.1 \%$ & $3,207,943$ & $13.7 \%$ \\
\hline$€ 20,001$ to $€ 50,000$ & 533,765 & $12.7 \%$ & 798,045 & $3.4 \%$ \\
\hline$€ 50,001$ to $€ 100,000$ & 212,675 & $5.1 \%$ & 271,481 & $1.2 \%$ \\
\hline$€ 100,001$ to $€ 500,000$ & 166,324 & $4.0 \%$ & 119,911 & $0.5 \%$ \\
\hline$€ 500,001$ to $€ 1,000,000$ & 2,570 & $0.1 \%$ & 5,019 & $0.0 \%$ \\
\hline$€ 1,000,001$ to $€ 3,000,000$ & 1 & . & 1,963 & $0.0 \%$ \\
\hline Over $€ 3,000,000$ & & . & 371 & $0.0 \%$ \\
\hline
\end{tabular}

Source: HFCS Austria 2010, OeNB; OeNB banking statistics.

${ }^{1}$ All cells marked with "." have no observation. 
customer relationships with higher deposits in the HFCS than in the banking statistics: some $81 \%$ of all accounts belong to the lowest category (holdings of up to $€ 10,000$ ) in the banking statistics, whereas only about $63 \%$ of the accounts captured by the HFCS have holdings in this range. This difference is then spread among the next highest categories. As the individual accounts in the banking statistics cannot be assigned to individual households, it cannot be determined whether the aggregation of accounts within a household explains the totality of the discrepancy.

The HFCS does not capture accounts with holdings above $€ 1$ million. Oversampling of wealthy households could improve the coverage of savings deposits in the HFCS. The probability of a household having savings deposits of over $€ 1$ million is highly unlikely, as only a total of about $0.03 \%$ of savings accounts are classified in the top three categories. Only about $0.0099 \%$ of savings accounts are classified in the top two categories in the banking statistics. Conversely, the HFCS covered a sufficient number of households with savings deposits of up to $€ 500,000$, and few households in the range in between.

\subsubsection{Savings Deposits Aggregate}

The total volume of savings deposits of domestic nonbanks in Austria is about $€ 156$ billion. The overwhelming majority (i.e., roughly $€ 150$ billion or $96 \%$ ) of this total can be attributed to households in the financial accounts. The remaining part is classified as "others". However, the total of the household sector as derived from the banking statistics cannot be broken down further into individual ranges and into banking sectors for the household sector. Therefore, the value of about $€ 156$ billion for total domestic nonbanks is used for the analysis, even though this leads to an overestimation on the side of the administrative data.

A detailed breakdown of the differences between HFCS and banking statistics data are shown in Table 4. In the first row, total savings deposits in all banking sectors are shown in the HFCS (panel 1) and in the banking statistics (panel 2). The third panel shows the HFCS to banking statistics ratio of each value. The HFCS results in the following tables are based on the information provided on savings deposits; this data is attributed to banking sectors on the basis of the bank at which a household holds the highest amount of deposits. The appendix contains equivalent tables based on national deposit variables.

The HFCS does not contain information about the two highest deposit categories. Consequently, assets in this part of the distribution are underestimated. The volume of savings deposits is also underestimated in the HFCS in the lower categories. For instance, in the savings deposit category $€ 100,000$ to $€ 500,000$, HFCS coverage comes to nearly $87 \%$ of the total aggregate, but to only $19 \%$ of total of savings deposits up to $€ 10,000$. This underestimation is attributable above all to the aggregation of savings accounts at the household level in the HFCS rather than the account level (banking statistics). This pattern is similar across all banking sectors. The higher estimate for the aggregate value (HFCS) in the middle savings deposit categories in the joint stock banking sector is also a consequence of the difference between unit of collection at the household and at the account level. The banking statistics data show a relatively larger number of deposit accounts among the lower deposit categories. These banking statistics data are not suited to showing the distribution of savings by households in Austria, only by accounts. In addition to what is already documented in the literature, we see in particular coverage rates in the different deposit categories and in the different banking sectors. 


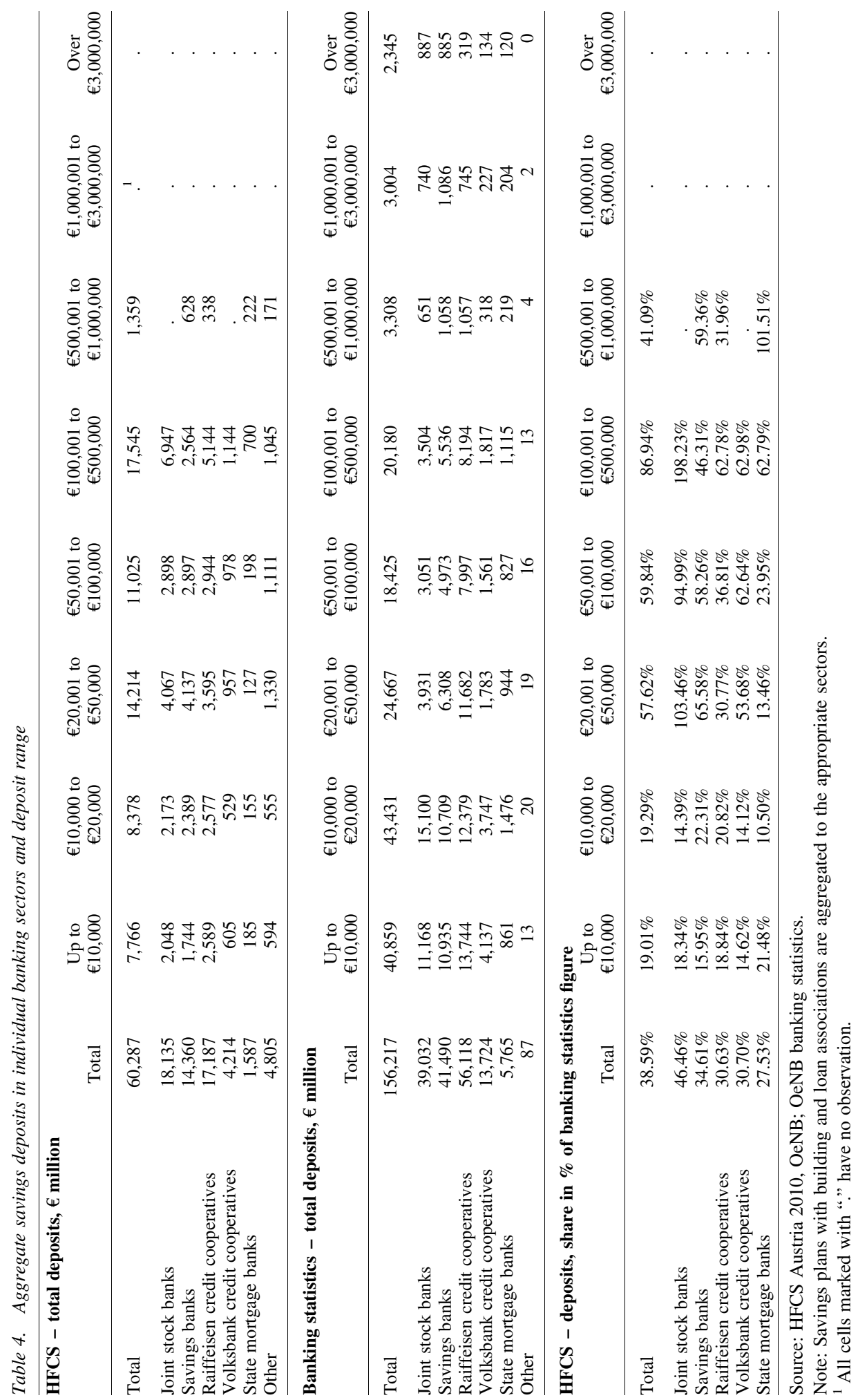


Table 5 additionally provides an analysis of the shares of individual banking sectors (left part) and deposit categories (right part) in total savings deposits.

The allocation of deposit holdings to the individual banking sectors is broadly the same in the HFCS and in the financial accounts. For instance, the smaller banking sectors (the Volksbank credit cooperatives and the mortgage banks) account for deposit shares of $7 \%$ and $3 \%$ according to HFCS data. The comparable banking statistics values are $9 \%$ and $4 \%$, respectively. Both data sources also show the three banking sectors holding the higher market shares of deposits. Only joint stock banks are shown to have a lower share and Raiffeisen banks a somewhat higher share in total deposits in the banking statistics.

According to the banking statistics more than two-thirds (roughly $70 \%$ in total) of all savings deposits are in savings accounts with holdings of less than $€ 50,000$ (see the right half of Table 5). The HFCS column features larger percentages of deposit holdings in higher categories due to the aggregation at the household level. Thus more than two-thirds of total savings deposits $(71 \%)$ are held in the categories spanning the range from $€ 20,001$ to $€ 500,000$. This is yet another area in which the household-level data from the survey complement the banking statistics data, as the preferred unit of evaluation is usually the household, not the individual account. Although deposits in the range from $€ 500,001$ to $€ 1.000,000$ account for $2 \%$ of the total volume in both data sources, the two top categories (four percent of the total volume in the banking statistics) are not covered in the HFCS. This means in particular that nearly seven percent of the total undercoverage in the HFCS can be attributed to the top two categories.

\subsubsection{Accounts with MFIs/Customer Relationships with Banks in the HFCS}

In order to explore further similarities and differences between the two data sources beyond the aggregates and aggregate shares, we analyse the allocation of customer relationships with banks in the HFCS and of the numbers of accounts in the banking statistics (see Table 6). The first row in the HFCS panel ("total") differs marginally from the results in Table 3, as the percentages cover only the customer relationship with the bank with the highest deposit holdings.

The distribution of customer relationships (HFCS) in the individual cells is very similar to the distribution in banking statistics. For example, $32.9 \%$ of accounts are held in the joint stock banking sector according to banking statistics, and $28.9 \%$ of households have accounts in the joint stock banking sector according to HFCS data. The gap in the Raiffeisen credit cooperative sector is even smaller at 30.5\% (banking statistics) versus $30.2 \%$ (HFCS). A broad view of all categories in the individual sectors reveals that the middle categories in all sectors are somewhat overestimated, whereas the categories at the upper and lower ends are underestimated in the survey. We should point out that less than $1 \%$ of accounts as shown by the banking statistics are in the category from $€ 100,001$ to $€ 500,000$ and that the HFCS estimates for this category are generally also of the same order (with the exception of the category joint stock banks). Hence, the HFCS appears to cover the customer relationship patterns quite well up to a level of about $€ 500,000$.

According to the banking statistics, all categories above $€ 500,000$ contain a maximum of $0.01 \%$ of accounts across all banking sectors. The HFCS contains nearly no observations above the level of $€ 500,000$. These figures once again show how unlikely it is that (enough) households with savings deposit holdings in excess of €500,000 will be 


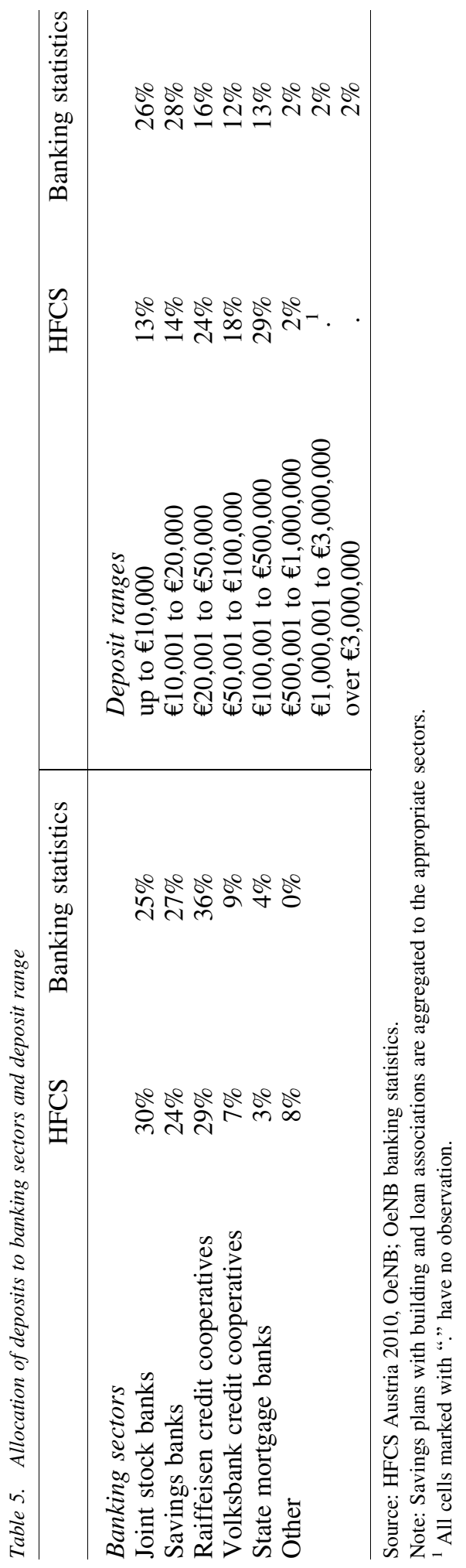




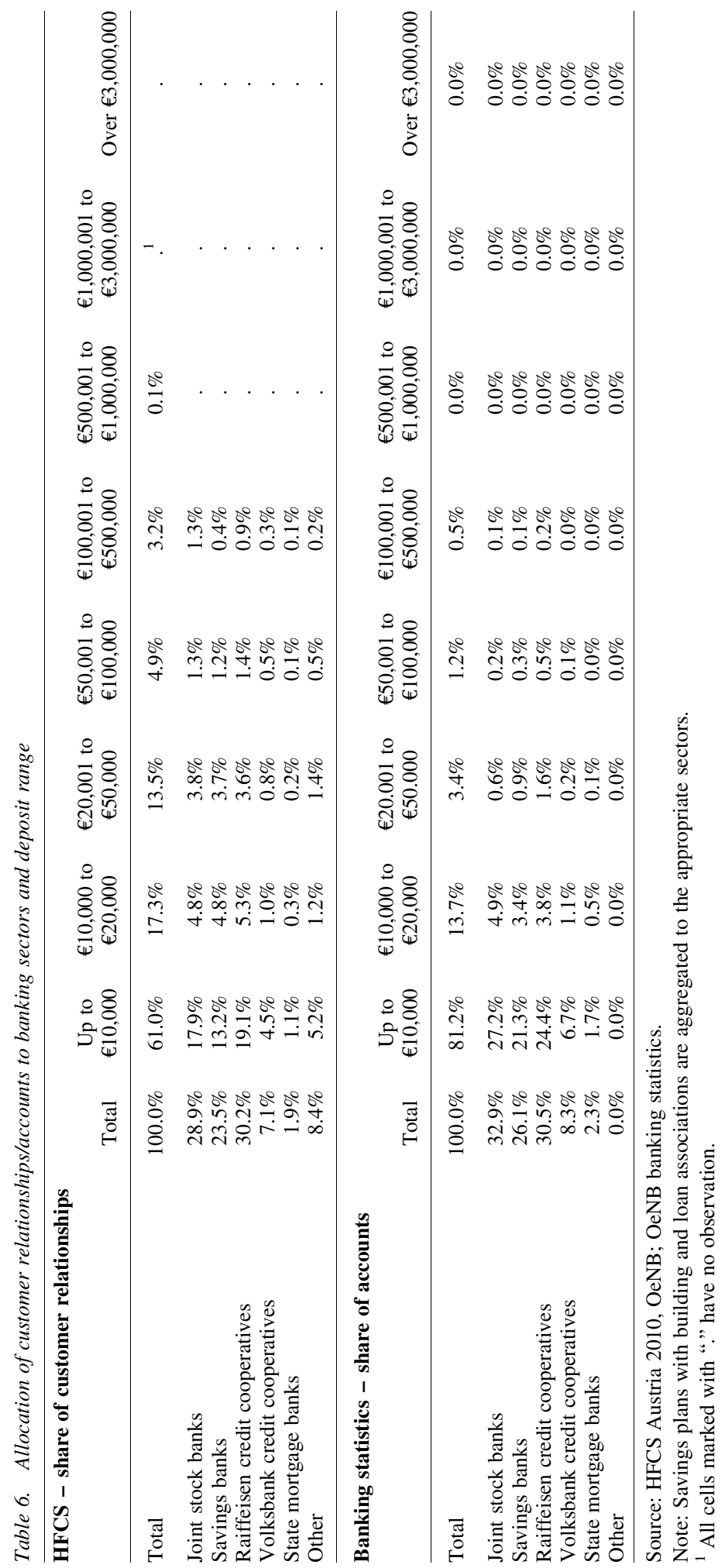


obtained. Appropriate oversampling of more affluent households in the survey might increase the chance of capturing the right tail of the distribution.

\subsubsection{Average Deposit Holdings in Banking Statistics/in the HFCS}

As the banking statistics data show both the volume of deposits and the number of accounts, the average holdings per accounts can be calculated. The arithmetic mean of deposits in households including the standard error of the estimator can also be estimated on the basis of the survey data. Table 7 shows the average deposit holdings broken down by deposit ranges and banking sectors for both data sources. For the HFCS data, the calculation of the standard error of the respective mean in a cell is based on 1,000 resampling weights contained in the HFCS data. A rescaled bootstrap procedure is the replication method used to construct the replicate weights. For details on the construction and use of these weights, see Albacete et al. (2012). Although it would be desirable to compare the whole distribution (or at least also the median), such a comparison cannot be made, as the banking statistics lack the relevant information.

Table 7 highlights two important aspects, namely (i) the total average of deposit holdings (Column 2) is higher according to the HFCS data than according to the banking statistics, and (ii) amounts above $€ 500,000$ are not covered, a confirmation of the known finding. The higher means are the result of the aggregation of individual accounts to household deposit holdings in the HFCS. The table shows clearly that the average amount of deposits in an account does not correspond to the average of Austrian households' savings deposit holdings, as households may have several accounts.

In the individual categories covered by the HFCS, the mean value of both data sources is similar. As a case in point, the average holdings of deposits in the range from $€ 100,001$ to $€ 500,000$ come to about $€ 168,000$ according to HFCS data (the standard error is roughly $€ 19,000$ ), thus matching the banking statistics average of about $€ 168,000$. Only in the first category - deposits up to $€ 10,000$ (and to a much lesser extent in the second category as well) - are the averages according to the banking statistics data far lower than the corresponding HFCS values. Savings accounts with very low deposits are responsible for this discrepancy. No large differences across banking sectors are observed, as the data from both sources confirm.

\section{Simulation of the Impact on some Key Indicators in the HFCS}

Finally, a look at the theoretical impact of coverage of the top deposit categories in the HFCS on commonly used statistics is able to provide some insights. The following simple simulation makes it possible to quantitatively assess how some indicators would change if the HFCS sample contained households with savings in the two top categories (savings of over $€ 1$ million). The HFCS already includes observations - albeit very few - in the category with savings of $€ 500,001$ to $€ 1,000,000$. The procedure simulates a few households with average holdings in the top two categories as available from the banking statistics. These households are assigned a weight, and the distributional indicators are then calculated with and without these households. The details of each step are laid out in the following paragraphs.

The household simulation is performed on the basis of the following assumptions: Two households with average holdings of $€ 6,320,000$ (average in the highest deposit range 


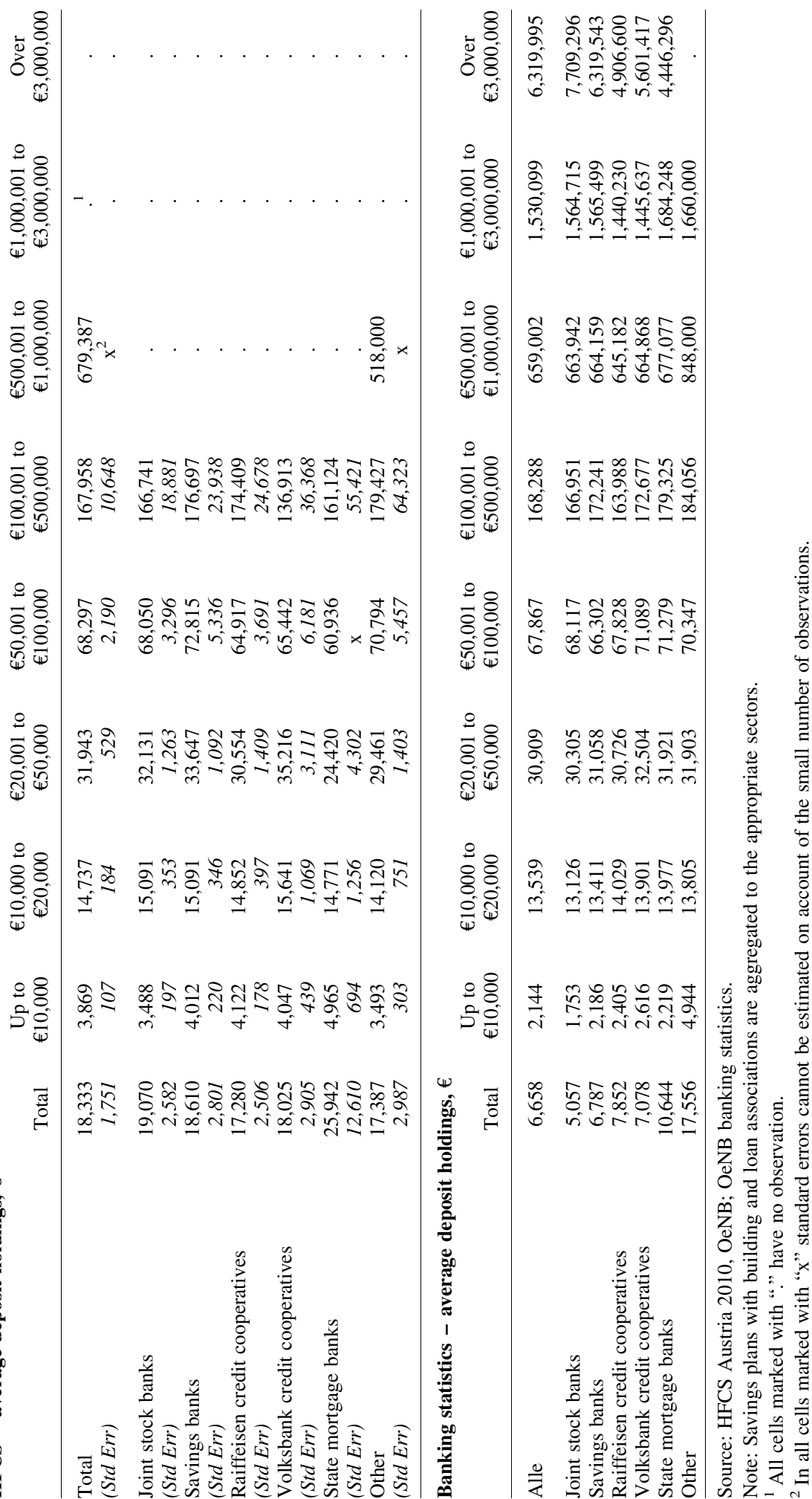


in the banking statistics) and four households with average savings deposits of $€ 1,530,000$ (average in the second-highest deposit range in the banking statistics) are imputed. While the assumption of the number of households is ad hoc, it is justified for two reasons: first, the assumption reflects the higher number of accounts in the second-highest deposit range in the banking statistics, and second, it allows for the assignment of different weights to the households.

Assuming that every household in Austria has the same number of savings accounts, there are roughly 330 households with accounts in the second-highest category and only about 60 households with accounts in the highest category. Hence, the nonresponseadjusted weights are assumed to be very $l \mathrm{w}^{3}$; that is, for the households in the top deposit range, the weight is 175 , or approximately the smallest nonresponse-adjusted weight in the original sample. For two households in the second-highest deposit range the nonresponseadjusted weight is set to 300 , or roughly the smallest percentile of these weights in the original sample. For the remaining two households in the second-highest category, this weight is set to 750 , or roughly the fifth percentile in the original sample. To influence the preparation of the survey as little as possible, the HFCS poststratification process in Austria was repeated with these newly simulated households. This last step in defining the final household weights is based on the nonresponse-adjusted weights as well as information on household size and the geographical distribution of households in Austria. For the simulated households, the information on household size and geographical location required for the poststratification process are randomized (uniform distribution). This means that the simulated households are assigned a random size of between one and six members (this corresponds to the minimum and maximum numbers of adult members in the households represented in the HFCS) and are assigned randomly to an Austrian province. In the poststratification procedure, the weights of the new total of 2,386 households are adapted in line with the distribution of household size and geographical location in Austria as taken from the Statistics Austria microcensus (see the HFCS documentation for Austria in Albacete et al. (2012)). After poststratification, the weights of the simulated households average 423 (408 prior to poststratification), whereas all other households have an average weight of around 1,600. The range of the weights changes from $150-750$ to $159.6-721.3$, that is, the range becomes smaller.

This simulation procedure reflects the relatively low number of accounts in the two top categories in the banking statistics. However, assuming an even distribution of the accounts, the six simulated households with an average weight of over 400 tend to overrepresent the roughly 400 households cited above. Thus it must be assumed that the simulation results represent the upper limit of the possible change.

Some of the most widely used indicators of the new sample can be compared with the estimators of the sample without the imputed households (original sample). The results are shown in Table 8.

Unsurprisingly, aggregate total savings deposits in Austria and average savings deposits are higher in the simulated sample. While the increase by $9 \%$ is economically significant, it cannot fully explain the entire underrepresentation (see Table 1 in Section 4). However,

3 Increasing these weights does not necessarily exert a clearly defined effect on the estimators, as the nonresponse-adjusted weights are poststratified. 
Table 8. Simulation results

\begin{tabular}{lrrr}
\hline & \multicolumn{3}{c}{ HFCS } \\
\cline { 2 - 4 } & $\begin{array}{c}\text { Original } \\
\text { sample }\end{array}$ & $\begin{array}{c}\text { Simulated } \\
\text { sample }\end{array}$ & $\begin{array}{c}\text { Change from } \\
\text { original sample }(\%)\end{array}$ \\
\hline Mean $(€)$ & 18,333 & 19,974 & $8.9 \%$ \\
Median $(€)$ & 6,985 & 6,994 & $0.1 \%$ \\
Gini & 0.681 & 0.706 & $3.7 \%$ \\
P90/P10 & 64.68 & 64.57 & $-0.2 \%$ \\
P90/P50 & 6.23 & 6.23 & $-0.1 \%$ \\
P10/P50 & 0.10 & 0.10 & $0.0 \%$ \\
Aggregate (€ million) & 60,287 & 65,731 & $9.0 \%$ \\
\hline
\end{tabular}

Source: HFCS Austria 2010, OeNB.

the quality of the simulation is also reflected by the absolute rise by some $€ 5$ billion, so that the aggregate in the top two categories of the banking statistics is fully covered. The impact on robust statistics such as the median or the percentile ratios is very small: the median of savings deposit amounts rises by just $0.1 \%$, for example. The impact on the ratios of the percentiles is also negligible in all parts of the distribution. The minimal reduction of P90/P10 and P90/P50 can be explained by the fact that the 90th percentiles increase less than the 10th and 50th percentiles on account of the simulation. Conversely, nonrobust statistics such as the Gini coefficient or the arithmetic mean of savings deposits change more strongly. Factoring in the simulated households causes the Gini coefficient to go up by some 2.5 points (about four percent of the rise in inequality as measured by the Gini coefficient). The reason for this fairly strong effect is the widening of the wealth bandwidth in deposits. In the original calculation, the Gini coefficient is calculated for a bandwidth of $€ 0$ to less than $€ 1$ million. The inclusion of the simulated households with holdings over $€ 6$ million has an effect on the Gini coefficient, even though these households have a low weight.

Overall, the simulation exercise shows that the HFCS is very well suited to capturing most of the distribution (see percentiles) even without generating information on the upper ranges of savings deposits. With respect to the other indicators, oversampling of the wealthy households - and thus achievement of a higher probability of capturing very high savings deposits - would be desirable, but the current indicators still deliver the best estimators for these statistics. Capturing the households with the holdings in the highest savings deposit ranges would, if anything, increase (but not decrease) the estimators for the aggregate, for the arithmetic mean, and for the inequality of savings deposits as measured by the Gini coefficient.

\section{Concluding Remarks}

This article examines the similarities and differences between data derived from surveys and from administrative sources, focusing on savings deposits as the main category of households' financial wealth in Austria. To this end, we compare the aggregate values, in line with the approach commonly described in the literature, and additionally compare a detailed breakdown of deposits by banking sectors and by deposit ranges, which has not 
been documented in the literature so far. Given the ex-ante harmonisation of the HFCS and the relatively similar structure of the relative importance of the components of financial wealth (see Figure 1), results are expected to be similar in other eurozone countries.

The main results of this analysis and what we can learn from them may be summarised as follows: the HFCS is well suited to identifying the (basic) deposit patterns, but estimates of total wealth are distorted downward, as has already been previously shown in the literature (and is discussed in Section 2). The underrepresentation of deposits across all banking sectors and deposit ranges and the lack of information on the highest deposit ranges are the reasons for this underestimation. Oversampling in the HFCS may contribute to closing this information gap at the tail of the distribution in the future (although due to the extremely low number of accounts in the highest ranges it is by no means guaranteed). The aggregate measures derived from administrative sources should provide a reliable estimator.

In addition, we consider the effects of the different units of aggregating savings deposits in the banking statistics (accounts based) and in the HFCS (household based). The banking statistics do not allow individual accounts to be allocated to households. The aggregation of accounts to the level of households, which is done the HFCS, results in a shift across deposit ranges. This shift indicates that even the data reported by the banks in the banking statistic cannot be used to analyse individual households, so that the HFCS provides highly useful additional information to the aggregates. Furthermore, the distribution across banking sectors and asset ranges of deposits is relatively similar in both data sources. Consequently, the two data sources are not meant to replace each other; much rather, they serve as complementary sources for analysing households in an economy where reliable distributional estimates can be calculated from the HFCS and aggregate values from the financial accounts. A final simulation of the top savings ranges indicates that the estimators (such as the Gini coefficient or the arithmetic mean) from the HFCS represent at least a lower bound for the true parameters, and that some indicators, in particular robust statistics such as the median and percentiles, are affected to a fairly low extent. The survey data provide a wealth of information that complement the administrative data and that are needed in particular to analyse certain groups of the respective target population.

Many other areas of the household accounts were not examined in this study, which focuses on financial assets and in particular savings deposits. Future research could be devoted to other components of financial wealth, such as equity wealth, or the debt side of the household balance sheet. A more in-depth comparison of data on real assets would also be desirable. However, very little useful administrative data on real assets is available. Furthermore, the investigation of measurement error that could not be achieved with the administrative records at hand should yield interesting insights.

\section{Appendix A: Explanatory Note on Data and Definition}

The data available allowed for a comparison not only of the aggregate values, but also of transferable deposits (F.22) and savings deposits (as a subcomponent of other deposits, F.29) in a particularly detailed way. Exploiting this detailed information from administrative sources provides the opportunity to extend the results in the literature, investigating financial assets, not only total values but also the distribution over asset ranges and banking sectors. 
The HFCS in Austria includes one question on sight accounts and two sets of questions on savings accounts. First, households are asked to specify the total amount of their savings deposits, broken down by (i) savings other than savings with building societies and (ii) savings with building societies (Note that life insurance funds must be subtracted from variable HD1210 of the version of the HFCS in Austria published by the ECB (this variable covers savings accounts) to ensure comparability with the values in the financial accounts). Building societies are banking entities that collect savings, usually from individuals, and grant preferential mortgage loans. Second, households are asked to indicate which banks they use based on a predefined list of the largest 21 banks and an additional verbatim recording for other institutions (up to five banks could be reported) and to specify how much money they hold in savings accounts and custody accounts at these banks, starting with the bank at which they hold the highest amount. The data from the first survey method are contained in the dataset published by the ECB as current account and savings account (including savings in building societies) information and therefore are used as the basis of comparison in this study. However, the ECB dataset does not contain any information about the allocation of households' savings to the individual sectors of the Austrian banking system, which is only available internally. The results of the comparison based on the second set of questions (amounts held at different banks) are in the Appendix B to this study as a sensitivity analysis and in general confirm the findings of the article.

As explained above, in the HFCS households were asked to indicate which banks they use rather than specifying the amounts held in individual accounts. If a household has several accounts at one and the same bank, the dataset records a customer relationship with a single bank. If a household has accounts at different banks, the dataset reflects customer relationships with several banks. The overwhelming majority of Austrian households use only a single bank - more than $91 \%$ of respondents in the HFCS - and only two percent of households have accounts with more than two different banks. However, households can be expected to have more than a single account with their so-called house bank. The first bank recorded, that is, the one at which the household holds the highest volume of funds, is also the one to which households are classified for the results in the article.

The deposit aggregates may be subdivided into sight accounts and savings deposits by bank sectors on the basis of the administrative account data that Austrian banks report to the OeNB. In addition, the total in savings accounts (only totals of domestic nonbanks, which include the self employed and sole proprietorships) may be further subdivided by deposit ranges. The data of the following bank sectors may be analysed separately:

- Joint stock banks

- Savings banks

- Raiffeisen credit cooperatives

- Volksbank credit cooperatives

- State mortgage banks

- Other

Raiffeisen and Volksbank are two types of credit cooperatives in the form of multistaged banks, which each form one separate banking sector in the banking statistics. Building societies are classified under the respective sector of the households' (house) bank, as customers associate their building society savings plans with their (house) bank. The 
category "other" is differently defined for the results from the HFCS and the banking statistics. In the HFCS, the households could choose to have a customer relationship with a bank from a predefined list of the 21 largest banks in Austria. In case the household wanted to state a different bank, a verbatim recording was available. If a respondent left the verbatim recording blank, the relationship was classified in the "other" category, since these responses could not be attributed to a banking sector ex post. In the banking statistics, "other" refers to special-purpose banks and banks as defined in Article 9 of the Austrian Banking Act (credit institutions from EU Member States). If a household has provided information about one of these banks in the verbatim text field, it was also classified to the category "other". Given the different definitions, no comparisons of this category were made; it is provided simply for the sake of completeness. Deposits can be allocated to the following ranges based on the administrative account data (the HFCS permits any type of classification):

- Up to $€ 10,000$

- $€ 10,000$ to $€ 20,000$

- $€ 20,000$ to $€ 50,000$

- $€ 50,000$ to $€ 100,000$

- $€ 100,000$ to $€ 500,000$

- $€ 500,000$ to $€ 1,000,000$

- $€ 1,000,000$ to $€ 3,000,000$

- Over €3 million

With data available in the banking statistics on both the number of accounts and the total volume of deposits, it is possible to calculate the average deposit holdings per account in a given deposit range for each and every bank sector separately. This average can be compared with the HFCS results for individual households. Due to the differences in the unit (account vs. household), however, one is expecting differences in the overall statistics since (potentially) several accounts are held by a single household (as explained above). Given the structure of the HFCS, where all accounts of a household are totalled, it might be expected that average deposits tend to be higher.

\section{Appendix B: Additional Results}

This appendix features three tables that repeat the calculations in Tables 4, 6, and 7 on the basis of the second way the information on the amounts (savings deposits) held at different banks was surveyed in the HFCS (see Appendix A). The use of data from this alternative survey method in the HFCS does not change the basic findings of the comparison of the HFCS and the financial accounts data. The appendix simply provides a sensitivity analysis for the classification of a household to a bank and for the different coverage methods of savings deposits. 


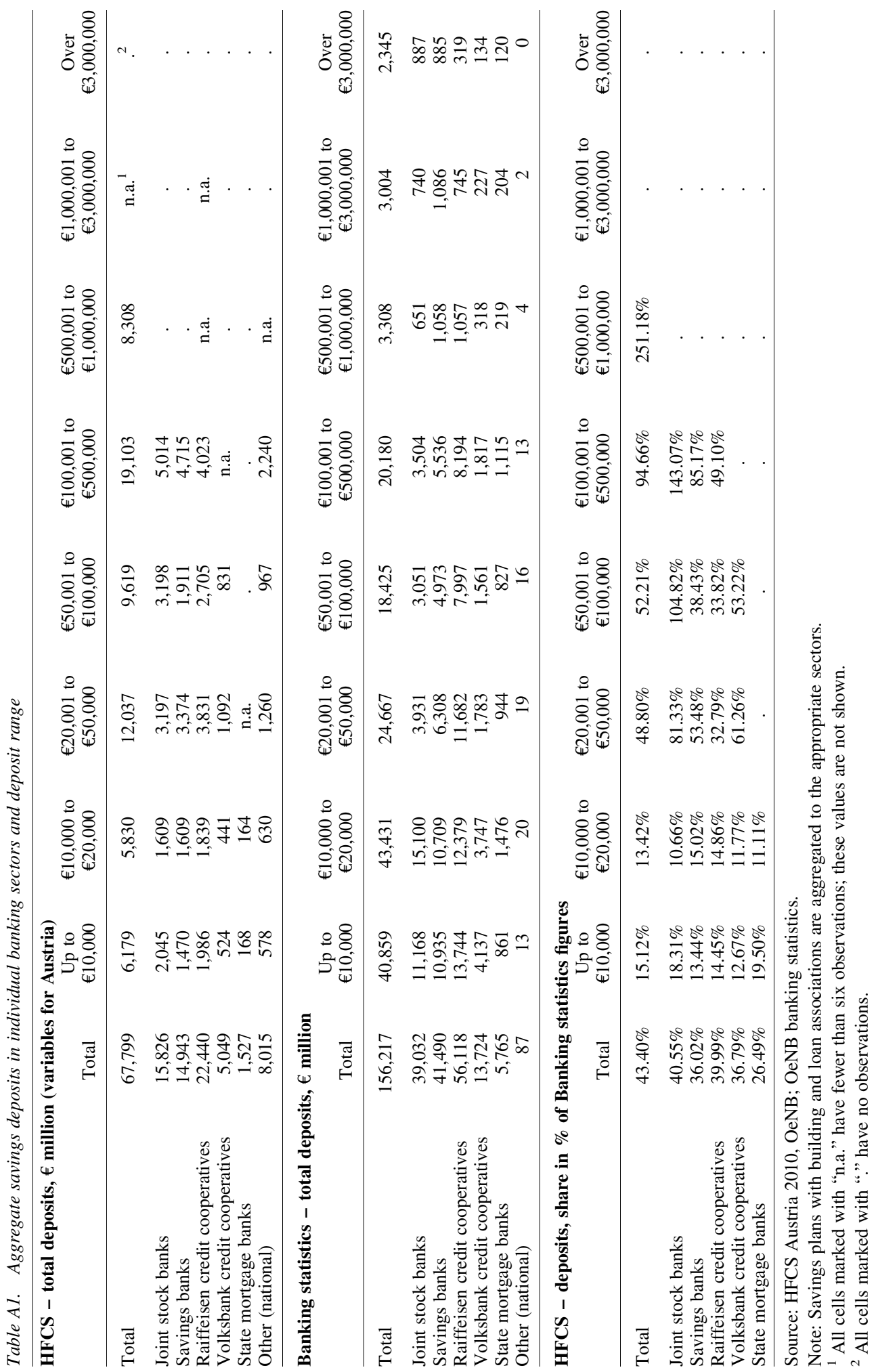




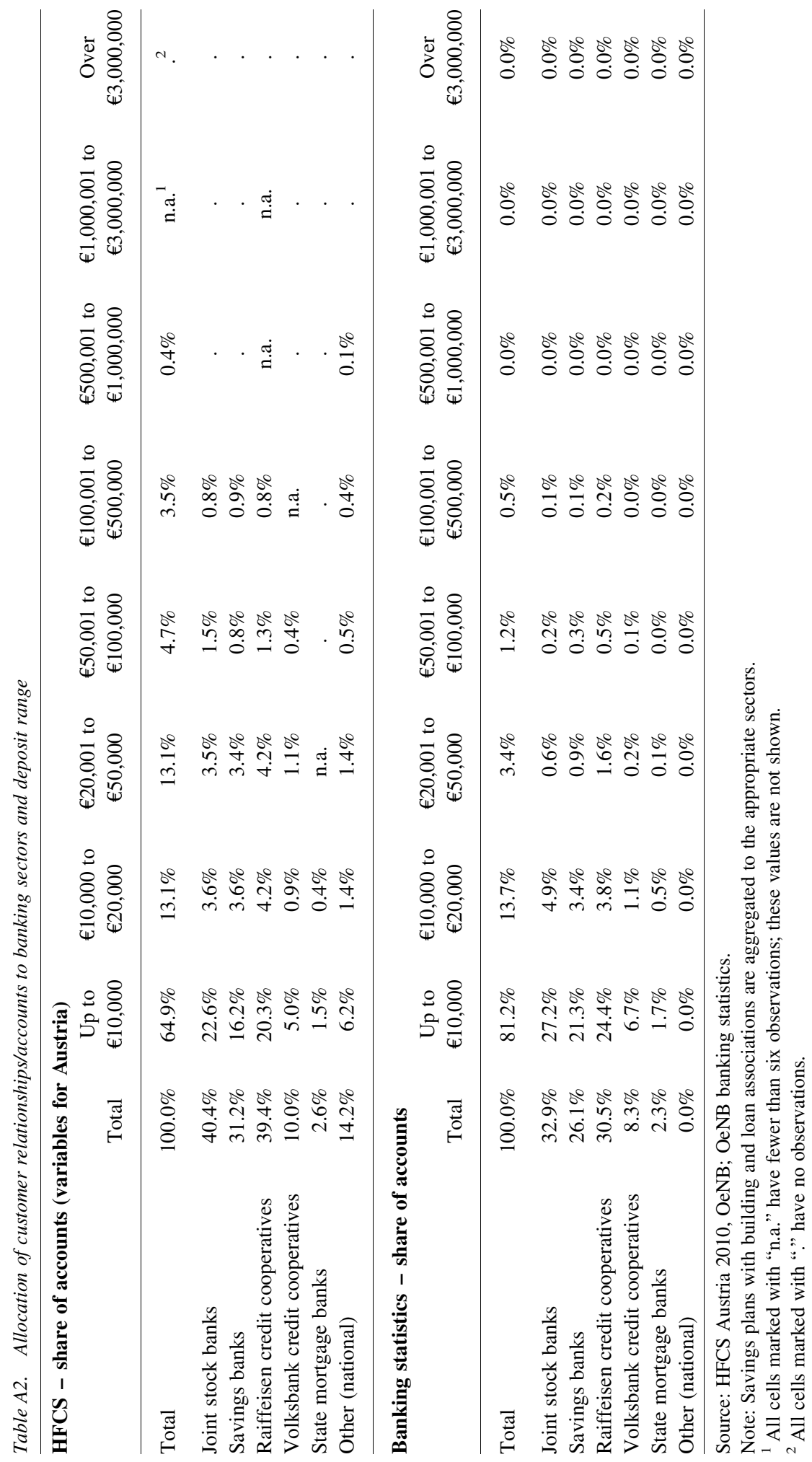




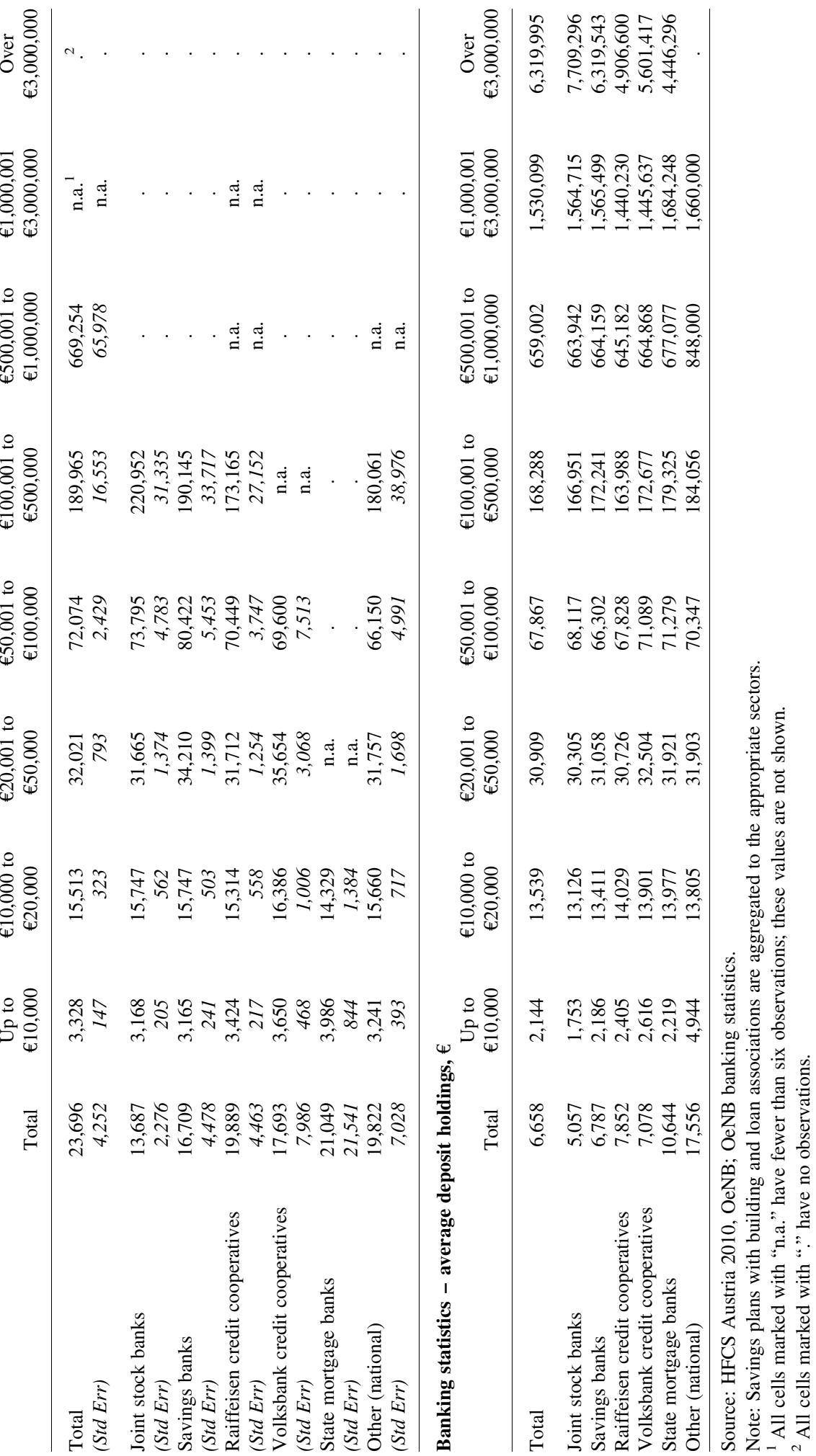




\section{References}

Albacete, N., P. Lindner, K. Wagner, and S. Zottel. 2012. "Eurosystem Finance and Consumption Survey 2010: Methodological Notes for Austria." Addendum to Monetary Policy and the Economy Q3/12: 1-100.

Andreasch, M., P. Fessler, and M. Schürz. 2009. “Austrian Households' Equity Capital Evidence from Microdata.” Monetary Policy and the Economy Q4/09: 61-78.

Antoniewicz, R., R. Bonci, A. Generale, G. Marchese, A. Neri, K. Maser, and P. O'Hagan. 2005. "Household Wealth: Comparing Micro and Macro Data in Canada, Italy and United States." Paper prepared for the LWS Workshop: "Construction and Usage of Comparable Microdata on Wealth: the LWS", Banca d'Italia, Perugia, Italy, 27-29 January 2005. Available at: http://www.lisproject.org/lws/introduction/files/ antoniewiczrevised.pdf (accessed 6 November 2012).

Avery, R.B., G.E. Elliehausen, and A.B. Kennickell. 1988. "Measuring Wealth with Survey Data: An Evaluation of the 1983 Survey of Consumer Finance." Review of Income and Wealth 34: 339-369.

Bricker, J. and G.V. Engelhardt. 2008. "Measurement Error in Earnings Data in the Health and Retirement Study." Journal of Economic and Social Measurement 33: 39-61.

Davies, P.S. and L.T. Fisher. 2009. "Measurement Issues Associated with Using Survey Data Matched with Administrative Data from the Social Security Administration." Social Security Bulletin 69: 1-12.

ECB. 2013. "The Eurosystem Household Finance and Consumption Survey - Results from the First Wave." Statistics Paper Series ECB 2: 1-111.

Fessler, P., M. Kasy, and P. Lindner. 2012. "Survey mode effects on income inequality measurement." Paper prepared for the 32nd General Conference of The International Association for Research in Income and Wealth. Available at: http://www.iariw.org/ papers/2012/LindnerPaper.pdf (accessed 2 December 2013).

Fessler, P., P. Mooslechner, and M. Schürz. 2012. "Eurosystem Household Finance and Consumption Survey 2010 - First Results for Austria." Monetary Policy and the Economy Q3/12: 24-62.

Henriques, A.M. and J.W. Hsu. 2014. "Analysis of Wealth Using Micro- and Macrodata: A Comparison of the Survey of Consumer Finances and Flow of Funds Accounts." In Measuring Economic Sustainability and Progress. National Bureau of Economic Research Studies in Income and Wealth (Book 72), edited by D.W. Jorgenson, J. Steven Landefeld, and P. Schreyer, 245-276. Chicago and London: University of Chicago Press.

Johansson, F. and A. Klevmarken. 2007. "Comparing Register and Survey Data." Chapter 2 in Essays on Measurement Errors and Nonresponse. Economic Studies 103. Ph.D. diss., Department of Economics, Uppsala University.

Kapteyn, A. and J.Y. Ypma. 2007. "Measurement Error and Misclassification: A Comparison of Survey and Administrative Data." Journal of Labor Economics 25: 513-551.

Kavonius, I.K. and J. Honkkila. 2013. "Reconciling Micro and Macro Data on Household Wealth: A Test Based on Three Euro Area Countries.” Journal of Economic and Social Policy 15: 1-30. 
Kavonius, I.K. and V-M. Törmälehto. 2010. "Integrating Micro and Macro Accounts The Linkages between Euro Area Household Wealth Survey and Aggregate Balance Sheets for Households." Prepared for the 31st General Conference of the International Association for Research on Income and Wealth, St. Gallen, 22-28 August 2010. Available at: http://www.iariw.org/papers/2010/7aKavonius.pdf (accessed 16 April 2015).

Kavonius, I.K., and V-M. Törmälehto. 2003. "Household Income Aggregates in Micro and Macro Statistics." Statistical Journal of the United Nations Economic Commission for Europe 20: 9-25.

Mathä, T.Y., A. Porpiglia, and M. Ziegelmeyer. 2012. "The Luxembourg Household Finance and Consumption Survey (LU-HFCS): Introduction and Results." Cahier D’Études Working Paper, Banque Centrale Du Luxembourg.

Roemer, M. 2002. "Using Administrative Earnings Records to Assess Wage Data Quality in the March Current Population Survey and the Survey of the Income and Program Participation." U.S. Census Bureau Technical Paper No. TP-2002-22. Available at: https://www.census.gov/hhes/www/income/publications/asa2002.pdf (accessed 16 April 2015).

Sierminska, E., A. Brandolini, and T.M. Smeeding. 2006. "Comparing Wealth Distribution across Rich Countries: First Results from the Luxembourg Wealth Study.” Luxembourg Wealth Study Working Paper Series 1. Available at: http://www. lisdatacenter.org/wps/lwswps/1.pdf (accessed 16 April 2015).

Stiglitz, J.E., A. Sen, and J.-P. Fitoussi. 2009. "Report by the Commission on the Measurement of Economic Performance and Social Progress." CMEPSP. Available at: http://www.stiglitz-sen-fitoussi.fr/documents/rapport_anglais.pdf (accessed 16 April 2015).

Törmälehto, V.-M. 2011. "Comparing National Accounts Income Aggregates with Income Aggregates based on LIS Micro-Data.” LIS Technical Working Paper Series 2. Revised version.

Received July 2014

Revised May 2015

Accepted August 2015 